\title{
Neuropharmacology of Alzheimer's Disease and Dementia
}

\author{
Yasar Sattar ${ }^{1 *}$, Mahwish Adnan ${ }^{2}$, Ramya Bachu $^{3}$ and Nirav Patel ${ }^{4}$ \\ ${ }^{1}$ Department of Internal Medicine, Icahn School of Medicine,USA \\ ${ }^{2}$ Department of Cognitive Behavioral Science, McMaster University, Canada \\ ${ }^{3}$ Department of Internal Medicine, Providence Hospital, USA \\ ${ }^{4}$ Department of Internal Medicine, Lasante Health,USA
}

Submission: September08, 2018; Published: October 15, 2018

*Corresponding author: Yasar Sattar, Department of Internal Medicine, Icahn School of Medicine at Mount Sinai-Elmhurst Hospital, New York, NY, USA; Tel: +17732735732; Email: Sattary@nychhc.org

Abstract

Alzheimer's disease (AD) is the leading cause of dementia and sixth-leading cause of death in the US. Medication in the management of this disease can bring better symptomatic control and increase the quality of life. There are a variety of medications targeting different receptors in the brain in the management of Alzheimer's disease. It is crucial for physicians to understand the neuropharmacology of therapeutic Alzheimer's disease medications. Some of the neurotransmitters involved in memory processing, synaptic transmission, neuronal growth and differentiation, excitatory/inhibitory balance, concentration, the motor control includes; Acetylcholine (Ach), Glutamate, Gamma-aminobutyric acid (GABA), Histamine, Serotonin/5-hydroxytryptamine (5-HT), and Dopamine respectively. Our editorial briefly explains the mechanism of action of drugs linked to the neurophysiology of Alzheimer disease.

Keywords: Alzheimer's disease; Acetylcholine; Glutamate; GABA; Histamine; Serotonin;Dopamine

Abbreviations: AD: Alzheimer's disease; ACH: Acetylcholine; GABA: Gamma-aminobutyric acid; 5-HT: 5-hydroxytryptamine

\section{Introduction}

Alzheimer's disease (AD) is the leading cause of dementia and sixth-leading cause of death in the US [1]. This editorial is a snapshot of neurotransmitters involved in $\mathrm{AD}$, as it is important to understand the mechanisms of therapeutic AD medications and the underlying pathophysiology of the disease.

\section{Acetylcholine}

Acetylcholine is crucial in memory processing in the central nervous system (CNS). Presynaptic cholinergic deficits, due to reductions in choline acetyl transferase and the loss of cholinergic generating neurons in the nucleus basalis of Meynert leads to low levels of acetylcholine, which can manifest in the form of cognitive, behavioral, and functional symptoms in AD patients. Therapy for $\mathrm{AD}$ begins with the goal of increasing acetylcholine levels by inhibiting acetylcholinesterase, which catalyzes the cleavage of acetylcholine into choline and acetate. Drugs providing symptomatic improvement by increasing acetylcholine levels through acetylcholinesterase inhibition include donepezil, rivastigmine, galantamine, and tacrine [2].

\section{Glutamate}

Glutamate, an abundant excitatory neurotransmitter in the CNS, has various functions, including learning and memory pro cesses, synaptic transmission, neuronal growth and differentiation, and synaptic plasticity. Glutamate primarily works through $\mathrm{N}$-methyl-D-aspartate (NMDA) receptors located in the postsynaptic membranes of neurons. In $\mathrm{AD}$, there is an increased presynaptic release of glutamate, as well as failed reuptake of released glutamate by astroglial cells in the synaptic cleft, causing tonic activation of NMDA receptors. The increased glutamate concentration in the synaptic cleft can trigger neuronal death due to $\mathrm{Ca}+2$-induced excitotoxicity via an NMDA receptor-mediated increase in intracellular $\mathrm{Ca}^{2+}$ concentration; this causes neuronal death through apoptosis and increased release of reactive oxygen-free radicals. Moreover, high glutamate levels in AD increase $\beta$-amyloid production; this positive feedback causes symptomatic deterioration. Memantine, an FDA-approved non-competitive glutamate-NMDA receptor antagonist, positively impacts cognition, mood, and behavior in AD patients by protecting cholinergic neurons from excitotoxicity [3].

\section{Gamma-Amino Butyric Acid}

Gamma-amino butyric acid (GABA), an inhibitory neurotransmitter in the CNS, is involved in learning and memory by maintaining the excitatory/inhibitory balance. GABAergic neurons are indirectly involved in memory processing by their extensive con- 
nections with cholinergic and glutaminergic neurons. GABAergic pathways are involved in the regulation of cognition, motor function, circadian rhythms, neural development, and adult neurogenesis. Most post-mortem studies of tissues from patients with $\mathrm{AD}$ have shown moderate to significant reductions in GABA levels in various cortical areas of the brain; particularly affected areas include frontal, temporal, and parietal cortices, possibly contributing to the behavioral and psychological symptoms of AD. Benzodiazepines and similar therapeutic agents act on GABA and help to control agitation and aggression in $\mathrm{AD}$; otherwise, these therapies are of limited use in AD, as their side effects greatly outweigh their benefits [4].

\section{Histamine}

Histamine plays a major role in cognitive function, along with the sleep-wake cycle, sensory and motor functions, energy, and endocrine homeostasis. Its function is mediated through H1, $\mathrm{H} 2$, H3, and H4 receptors. Particularly, the H3 receptor is crucial in the CNS, as it inhibits histamine release. Studies have shown contradictory results regarding the histaminergic system in AD. Some studies showed a reduced concentration of histamine levels in the hippocampus, and frontal/temporal cortices of $\mathrm{AD}$ patients. Other studies have reported elevated levels of histamine in the frontal cortex, basal ganglia, and hippocampus. Histamine receptor antagonists have been studied in animal models; thioperamide, clobenpropit, and pitolisant an H3R antagonist, useful in narcolepsy and schizophrenia) could reverse partial loss of cognitive functions in mouse and rat models of amnesia [5].

\section{Serotonin}

Serotonin, or 5-hydroxytryptamine (5-HT), is a neurotransmitter that is active in short and long-term memory processing in the frontal cortex and hippocampus. It is also responsible for pain, hunger, emotions, sleep-wake cycle, motor, and sexual functions. In $\mathrm{AD}$, abundant $\mathrm{A} \beta$ plaques and neurofibrillary tangles can damage serotonergic neurons in the dorsal and median raphe nuclei. This loss of neurons progresses with age due to increased accumulation of $A \beta$ plaques and neurofibrillary tangles. Reduced serotonergic neurotransmission in $\mathrm{AD}$ also results from reductions in serotonin transporter binding sites and pathologic modifications of 5-HT receptor subtypes. Several studies have examined the effects of 5-HT drugs on cognitive function in AD.

Notably, selective serotonin reuptake inhibitors (SSRIs; e.g., citalopram, sertraline, or fluoxetine) have shown consistent improvement in behavioral symptoms in AD patients, including depression, agitation, irritability, anxiety, affective symptoms, and aggressive behavior. Another approach involves a combination of acetylcholinesterase inhibitors (AChEIs) and SSRIs; this treatment induces significant improvement in memory and cognition by increasing cerebral metabolism. Notably, clinical studies have reported improvement in the performance of daily activities in patients with $\mathrm{AD}$ who are treated by this combined approach. In $\mathrm{AD}$ patients with depression, treatment with a combination of AChEIs and monoamine oxidase inhibitors resulted in improvements in agitation, depressive behavior, and episodic memory. Serotonin and norepinephrine reuptake inhibitors (venlafaxine or milnacipran) have also shown benefits in depressive behavior in $\mathrm{AD}$ patients [6,7].

\section{Dopamine}

Dopamine, a neurotransmitter, plays a significant role in executive function, motor control, motivation, arousal, reinforcement, and reward responses. Dopamine-containing neurons are primarily located in the midbrain, within the substantia nigra and ventral tegmental areas. During aging, there is a decline in dopamine neurotransmission and release from synaptic terminals, thus inducing hypoactivity, gait disturbances, and reduced executive functioning. Extrapyramidal signs, such as bradykinesia, face masking, tremors, and gait disturbances may occur in AD, especially in patients treated with neuroleptics. Apathy and extrapyramidal motor deficits are secondary to dopamine dysfunction; their appearances have a negative prognostic value and they indicate disease progression in AD patients. Earlier DA dysfunction indicates faster cognitive decline. Electrophysiological studies performed on AD patients showed positive effects of DA drugs on cortical neurotransmission, synaptic plasticity, and cognitive performance, suggesting therapeutic benefits of these drugs in the treatment of AD. Rotigotine, a dopamine agonist, has beneficial effects on some cognitive domains in $\mathrm{AD}$ patients [8,9].

\section{Conflict of Interest}

The authors declare that the research was conducted in the absence of any commercial or financial relationships that could be construed as a potential conflict of interest.

\section{Author Contribution}

YS drafted the preliminary manuscript and MA reviewed the data online to summarize. RB and NP finalized the manuscript.

\section{Funding}

The authors declare that no funding was provided for this editorial.

\section{Acknowledgments}

None.

\section{References}

1. Alzheimer's Association (2018) 2018 Alzheimer's Disease Facts and Figures. Alzheimers Dement 14(3): 367-429.

2. Agatonovic-Kustrin S, Kettle C, Morton DW (2018) A Molecular Approach in Drug Development for Alzheimer's Disease. Biomedicine \& Pharmacotherapy 106: 553-565.

3. Revett TJ, Baker GB, Jhamandas J, Kar S (2013) Glutamate System, Amyloid $\beta$ Peptides and Tau Protein: Functional Interrelationships and Relevance to Alzheimer Disease Pathology. J Psychiatry \& Neuroscience 38(1): 6-23.

4. Lanctot KL, Herrmann N, Mazzotta P, Khan LR, Ingber N (2004) GABAergic function in Alzheimer's Disease: Evidence for Dysfunction and Potential as a Therapeutic Target for the Treatment of Behavioral and Psychological Symptoms of Dementia. Can J Psychiatry Rev 49(7): 439-453. 
5. Nieto-Alamilla G, Marquez-Gomez R, Garcia-Galvez AM, MoralesFigueroa GE, Arias-Montano JA (2016) The histamine H3 receptor: structure, pharmacology, and function. Mol Pharmacology 90(5): 64973.

6. Kandimalla R, Reddy PH (2017) Therapeutics of Neurotransmitters in Alzheimer's Disease. J Alzheimer's Dis 57(4): 1049-1069.

7. Rodriguez JJ, Noristani HN, Verkhratsky A (2012) The Serotonergic System in Ageing and Alzheimer's Disease. Prog Neurobiology 99(1): 15-41.
8. Neuroprotection and Neurodegeneration (2011) Biochimica Biophysica acta 1808: 1380-99.

9. Martorana A, Koch G (2014) “Is Dopamine Involved in Alzheimer's Disease?". Front Aging Neuroscience 6: 252.

\section{Your next submission with Juniper Publishers will reach you the below assets}

- Quality Editorial service

- Swift Peer Review

- Reprints availability

- E-prints Service

- Manuscript Podcast for convenient understanding

- Global attainment for your research

- Manuscript accessibility in different formats ( Pdf, E-pub, Full Text, Audio)

- Unceasing customer service

Track the below URL for one-step submission https://juniperpublishers.com/online-submission.php 